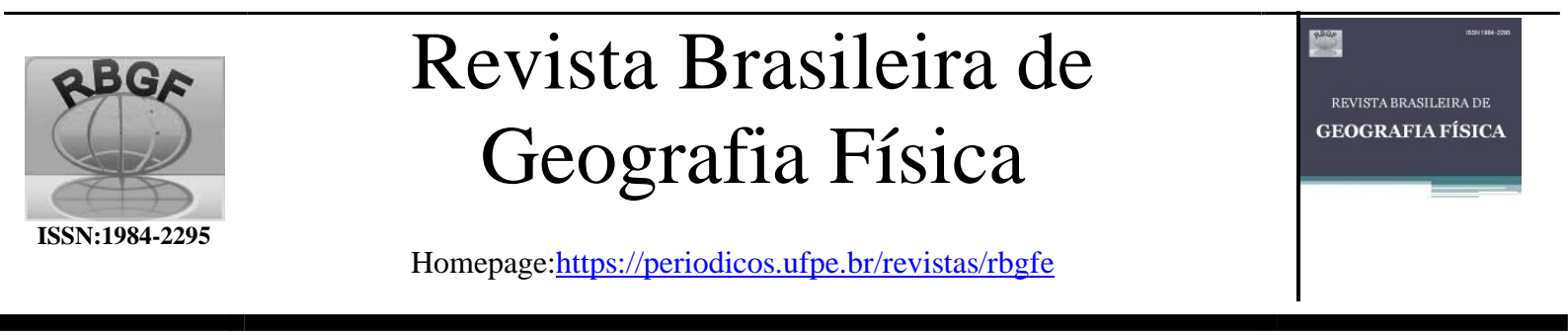

\title{
A participação social nas audiências públicas nos processos de Licenciamento Ambiental de empreendimentos minerários em Minas Gerais
}

\author{
Guilherme Prado Alves - e-mail? pradoalvesguilherme@ gmail.com (autor correspondente), Universidade \\ Federal de Itajubá, Ana Luiza de Souza Marcondes, Universidade Federal de Itajubá; Maria Elisa Diniz \\ Bucci, Universidade Federal de Itajubá; Maria Rita Raimundo e Almeida, Universidade Federal de Itajubá
}

Artigo Submetido em 26/05/2020 e aceito em 11/08/2020

\begin{abstract}
R E S U M O
A mineração é uma das bases da economia brasileira e, por causar impactos socioambientais, está sujeita ao licenciamento e avaliação de impacto ambiental que envolve a participação social. Entretanto, a literatura aponta que a participação dentro desses processos possui limitações. Destarte, este trabalho objetivou descrever a participação social nas audiências públicas dos processos de licenciamento ambiental de empreendimentos minerários em Minas Gerais após a implementação do sistema de "Consulta e Requerimento de Audiência Pública". Para isso, foram utilizados os dados disponibilizados no sítio eletrônico deste sistema de solicitações e realização das audiências públicas entre julho/2018 e novembro/2019. Para as audiências realizadas, foram levantados, por meio da ata, alguns pontos de interesse. Inicialmente, observou-se a ausência de solicitação em $85 \%$ dos 143 processos. No entanto, no que se refere à mineração, foram encontrados 12 processos, sendo que dois terços já contavam com audiência (solicitada, agendada ou realizada). Os principais solicitantes das audiências foram entidades civis e autoridades locais. As audiências realizadas mostraramse acessíveis e favoráveis à participação nos quesitos horário, local, presença de lideranças comunitárias e membros da sociedade civil. Já a linguagem utilizada apresentou características distintas, sendo não adequada à participação em alguns casos. Em síntese, a participação sob a forma de audiência pública, tão ausente nos processos de licenciamento mineiros, esteve mais presente quando se tratava de mineração, o que pode ser resultado dos recentes desastres. Não realizar audiência indica uma fragilidade do processo, porém, sua realização não é garantia de efetiva participação.

Palavras-chave: Audiência pública, Avaliação de Impacto Ambiental, mineração, participação social, Minas Gerais.
\end{abstract}

\section{Social participation in public hearings in the Environmental Licensing processes of mining in Minas Gerais State - Brazil}

\begin{abstract}
Mining is one of foundations of the Brazilian economy and causes socio-environmental impacts, and then it is subject to licensing and environmental impact assessment process that involves social participation. However, the literature points out that participation within licensing processes has limitations. Thus, this work aimed to describe the social participation in public hearings of the environmental licensing processes of mining in Minas Gerais State, after implementation of the "Public Hearing Consultation and Request" system. For this, data available on website of requests and conducting of public hearings from July/2018 to November/2019 were used. For hearing held, some points of interest were raised through minutes. Initially, the absence of requests was observed in $85 \%$ of 143 cases. However, with regard to mining activities, 12 cases were found, of which two thirds already had the audience (requested, scheduled or carried out). The main requesters for hearings were civil entities and local authorities. The hearings held proved to be accessible and favorable to participation in terms of time, place, community leaders presence and civil society members. The language used in the hearings presented different characteristics, being not suitable for participation in some cases. In summary, participation in form of a public hearing, so absent in the licensing processes in Minas Gerais, was more present when it came to mining, which may be result of the recent disasters. Not having a public hearing indicates a weakness; however, its performance is not a guarantee of effective participation.
\end{abstract}

Keywords: Public hearing, Environmental Impact Assessment, mining, public participation, Minas Gerais State. 


\section{Introdução}

A economia brasileira é baseada, principalmente, na exploração e extração de recursos naturais (Carvalho et al., 2018). Assim, a indústria extrativista mineral recebe grande destaque, representando $1,4 \%$ do Produto Interno Bruto (PIB) e gerando empregos diretos para cerca de 195 mil trabalhadores, segundo o relatório anual do Instituto Brasileiro de Mineração (IBRAM). Além disso, é um segmento importante no fomento à atividade industrial no Brasil, uma vez que fornece matéria-prima necessária à realização de diversas atividades econômicas no país (IBRAM, 2019).

No entanto, as atividades desempenhadas pelas empresas mineradoras afetam diretamente $o$ meio ambiente e a comunidade, sendo necessária a realização de um processo de licenciamento ambiental para a sua implantação e operação (Silva e Andrade, 2017). Neste sentido, a legislação federal brasileira elenca as atividades minerárias como aquelas que dependerão em seu processo de licenciamento da elaboração tanto do Estudo de Impacto Ambiental (EIA) quanto do Relatório de Impacto Ambiental (RIMA) (CONAMA, 1986).

$\mathrm{O}$ processo de licenciamento ambiental é de extrema valia em relação tanto às atividades desempenhadas pela mineração e seus impactos socioambientais, quanto à ocorrência de desastres relacionados ao rompimento de barragens. Por exemplo, existem evidências que falhas no processo de licenciamento ambiental, envolvendo insuficiência de dados e estudos relevantes sobre a obra, estariam diretamente relacionadas ao rompimento da barragem de Fundão, em Mariana/MG (Wanderley et al., 2016).

Há, ainda, um vínculo entre o processo de licenciamento ambiental e outro instrumento da Política Nacional de Meio Ambiente: a Avaliação de Impacto Ambiental (AIA). Nos casos em que os empreendimentos e atividades poluidoras são capazes de causar significativa degradação ambiental, o processo de licenciamento fica condicionado à realização da AIA (Almeida et al., 2018). Esta se constitui, basicamente, por estudos realizados para identificar, prever e interpretar atividades que possam vir a causar algum dano à saúde e ao bem-estar da sociedade, buscando prevenir possíveis danos e informar sobre os efeitos ambientais decorrentes destas atividades (Bolea, 1984).

Entre as etapas da AIA, prevê-se a participação (Sanchéz, 2013), que pode ser anunciada como o abarcamento de pessoas e grupos que irão sofrer os efeitos benéficos ou maléficos de uma intervenção proposta que deve passar por um processo de decisão (IAIA, 2006). A participação pública dentro da AIA pode contribuir com o processo em diversos momentos como na triagem, na preparação do escopo, durante a elaboração dos estudos de impacto ambiental, durante a análise do estudo por parte do órgão ambiental, além da etapa de monitoramento (Almeida e Montaño, 2015). No entanto, no Brasil, essa participação é legalmente exigida somente após a conclusão do EIA, quando já existe um quadro completo da situação caso o empreendimento seja implantado (Sánchez, 2013). Sua regulamentação é dada pela Resolução do Conselho Nacional do Meio Ambiente (CONAMA) $n^{\circ}$ 09/1987 e deve ocorrer sob a forma de audiências públicas (CONAMA, 1987). Cabe destacar que a participação pública em um processo de licenciamento/AIA não se resume à realização da audiência pública. No entanto, devido ao arranjo legal no país, ela pode ser considerada como o principal evento participativo.

Dentro do contexto jurídico, Moreira Neto (1997) afirma que: o instituto da audiência pública é um processo administrativo de participação aberto a indivíduos e a grupos sociais determinados, visando ao aperfeiçoamento da legitimidade das decisões da Administração Pública, criado por lei, que the preceitua a forma e a eficácia vinculatória, pela qual os administrados exercem o direito de expor tendências, preferências e opções que possam conduzir o Poder Público a decisões de maior aceitação consensual.

No âmbito do licenciamento ambiental, a audiência pública é a reunião pública, aberta e acessível destinada a esclarecer dúvidas e recolher críticas ou sugestões acerca do processo de licenciamento ambiental, expondo aos interessados informações sobre a atividade ou o empreendimento objeto do requerimento de licença e oferecendo-lhes possibilidades concretas de participação na construção das decisões administrativas correspondentes (COPAM, 2018). Embora seja um valioso instrumento para a democratização da tomada de decisão, a audiência pública ainda apresenta inúmeras limitações como forma de participação (Sanchéz, 2013). Para Burian (2006), por exemplo, as audiências públicas são insuficientes para a população dar sua contribuição na decisão.

Conforme a Resolução CONAMA $n^{\circ}$ 09/1987, as audiências públicas são realizadas somente nos casos de licenciamento apoiados em EIA/RIMA (CONAMA, 1987). Porém, ainda nesses casos, a realização de audiência pública não 
é certa: ela só irá acontecer se o órgão ambiental julgar necessário ou se for exigida pelo Ministério Público, por entidade civil ou por cinquenta ou mais cidadãos (CONAMA, 1987). Em resumo, Almeida et al. (2018) afirmam que só existe a obrigatoriedade da publicidade do processo com a possibilidade de solicitação e realização da audiência e participação pública, mas ela só acontecerá uma vez solicitada.

Em Minas Gerais, a participação nos processos de Licenciamento e AIA era regulamentada pela Deliberação Normativa do Conselho Estadual de Política Ambiental (COPAM) $\mathrm{n}^{\text {o }}$ 12/1994 (COPAM, 1994), que reproduzia o estabelecido na Resolução CONAMA $\mathrm{n}^{\circ}$ 09/1987 (CONAMA, 1987). No entanto, em 2018, ela foi substituída pela Deliberação Normativa do COPAM n ${ }^{\circ} 225$ (COPAM, 2018). Segundo Almeida et al. (2019), no novo instrumento legal foram alterados os solicitantes da audiência (sendo acrescido o prefeito do município sede ou prefeito de município sujeito aos potenciais impactos ambientais da atividade ou empreendimento e o próprio empreendedor), a organização da audiência sofreu algumas alterações na distribuição de tempo e ocorreu a inclusão dos meios digitais para a divulgação das informações relacionadas à solicitação e realização da audiência, bem como para disponibilização do RIMA e transmissão online e em tempo real da audiência; continua-se, no entanto, prevendo a participação pública apenas após a elaboração dos estudos ambientais.

Nesse sentido, verifica-se que a participação social e o acesso à informação são de extrema importância em processos de licenciamento ambiental, sendo esses mecanismos formas de garantir a justiça ambiental e assegurar o direito ao acesso a um meio ambiente equilibrado por toda a população (Patriarcha-Graciolli e Carvalho, 2013). Partindo desse princípio e levando em consideração o protagonismo garantido às populações pelos instrumentos de políticas ambientais brasileiros, o presente trabalho tem como objetivo descrever a participação social nas audiências públicas dos processos de licenciamento ambiental de empreendimentos de mineração no estado de Minas Gerais após a implementação do sistema de "Consulta e Requerimento de Audiência Pública" e por meio das informações disponibilizadas por ele. Informações estas que são públicas e de fácil acesso a qualquer interessado.

\section{Material e Métodos}

Este trabalho trata-se de uma pesquisa documental de caráter descritivo, conforme as definições de Gil (2002). A abordagem da problemática associada à participação pública nos processos de licenciamento de empreendimentos mineradores no Estado de Minas Gerais é apresentada por meio de um levantamento e descrição de informações disponibilizadas no sítio eletrônico da Secretaria de Estado de MeioAmbiente e Desenvolvimento Sustentável de Minas Gerais (SEMAD-MG). A página de "Consulta e Requerimento de Audiência Pública" (http://sistemas.meioambiente.mg.gov.br/licencia mento/site/consulta-audiencia) conta com um banco recente de dados que foi acessado. Isto é resultado da Deliberação Normativa do COPAM n ${ }^{\circ}$ 225/2018 que promoveu a inclusão dos meios digitais para a divulgação das informações relacionadas à solicitação e realização da audiência (COPAM, 2018).

Nesse espaço, é possível encontrar informações sobre os empreendimentos submetidos ao processo de licenciamento ambiental que são passíveis de audiências públicas em Minas Gerais desde o dia 19/07/2018. É um horizonte temporal recente, mas representa a única sistematização concentrada de informações em um banco de dados sobre audiências públicas em Minas Gerais. Assim, o recorte temporal analisado nesta pesquisa corresponde ao período de julho de 2018 a novembro de 2019 , sendo os dados obtidos no sítio eletrônico em 01/12/2019, quando se iniciou a análise dos dados. O portal apresenta, ainda, o status das audiências públicas nesses processos, classificado em: aguardando solicitação, audiência solicitada, audiência agendada, audiência realizada, ausência de solicitação e audiência cancelada.

Inicialmente, foi realizado um levantamento geral e quantitativo da realização de audiências públicas em todos os processos disponibilizados para em seguida focar nas atividades minerárias. A delimitação inicial do objeto de estudo deste trabalho ocorreu por meio do filtro dos empreendimentos presentes no banco de dados, utilizando o campo "Atividade(s) do Empreendimento". Já que o interesse era de processos de licenciamentos de empreendimentos minerários, foram selecionados aqueles caracterizados como Listagem A que, segundo a Deliberação Normativa COPAM no 217/2017, correspondem às atividades minerárias (COPAM, 2017). Partindo desses dados, foi realizada uma 
análise quantitativa das solicitações de audiências públicas ligadas à mineração no Estado.

Em seguida, foi aplicado um novo filtro, dessa vez no campo "Status", que permitiu a seleção das audiências públicas que já foram realizadas. Nesses casos, foram selecionados os processos em que as audiências públicas ocorreram e analisadas as suas atas, documentos que transcrevem as falas, com o intuito de realizar um diagnóstico da participação social nestes processos e durante este evento. A análise das atas foi realizada utilizando os seguintes pontos, adaptados de Maia (2016): horário da audiência; local da audiência; linguagem utilizada e forma de apresentação do projeto e impactos; tempo de fala dos manifestantes; participação de lideranças comunitárias e de membros independentes da sociedade civil; fornecimento de transporte para a audiência pública; existência de lista de presença e número de participantes.

Todos os dados sistematizados permitiram a construção de um diagnóstico descritivo da participação social nas audiências públicas realizadas em processos de licenciamento de empreendimentos minerários em Minas Gerais após a implementação do novo sistema, fundamentando a discussão e análise de resultados.

\section{Resultados e Discussão}

Visando combater à desinformação, o sistema eletrônico da SEMAD-MG, proposto pela Deliberação Normativa do COPAM $\mathrm{n}^{\circ} 225$ (COPAM, 2018), apesar de ser recente, apresentase como uma ferramenta aberta à população, permitindo que esta possa utilizá-lo para tomar ciência sobre detalhes associados a empreendimentos geradores de impacto ambiental, bem como solicitar audiências públicas nos casos que julgar pertinente. Logo, o sistema representa uma maior facilidade no processo de requerimento de audiência, já que os interessados podem facilmente fazer este processo. Isto pode levar a pensar que mais audiências seriam solicitadas, cabendo aos dados aqui apresentados também avaliar esta afirmação.

Ainda, é necessário destacar que este banco de dados demonstra as diversas situações das audiências públicas no estado Minas Gerais. Considerando o prazo máximo para solicitação de audiências públicas até 30 de novembro de 2019 , constam, desde julho de 2018, 143 processos de licenciamento no banco de dados. Esses processos referem-se a empreendimentos de todas as tipologias, cujas características e classificação são definidas na Deliberação Normativa do COPAM n ${ }^{\circ}$ 217 (COPAM, 2017).
Dos 143 processos de licenciamento listados, referentes a qualquer tipologia de empreendimento, no prazo delimitado: 3 tiveram audiência agendada; 1 teve audiência cancelada; 6 tiveram audiência realizada; 6 tiveram audiência solicitada; 5 estavam aguardando solicitação; e 122 não tiveram solicitação. A Figura 1 ilustra a distribuição do status das audiências públicas.

Nota-se que não houve solicitação de audiência pública em $85 \%$ dos casos. Situação semelhante foi encontrada em Almeida et al. (2018): dentre os 79 processos de licenciamento ambiental que abriram edital de solicitação de audiência pública tramitados na Superintendência Regional de Regularização Ambiental do Triângulo Mineiro e Alto Paraíba, entre 2009 e 2015 , apenas $18 \%$ tiveram convocação do evento. Logo, comparando os resultados do presente trabalho, após a implantação do sistema eletrônico de requerimento de audiência, com um trabalho anterior, percebe-se que a maior facilidade de requerimento da audiência trazida pelo novo sistema não refletiu em um número alto de solicitações.

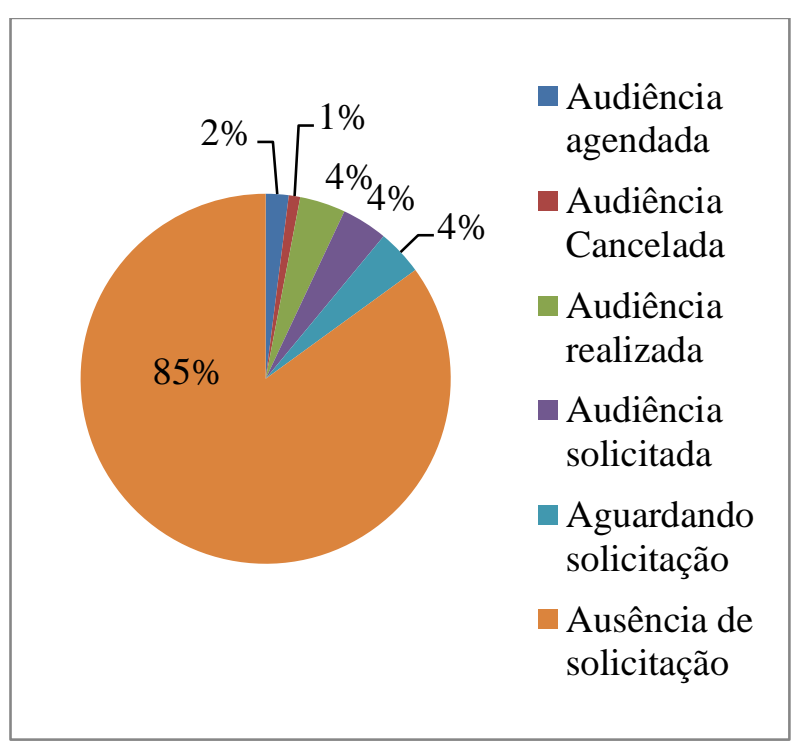

Figura 1. Status dos processos de solicitação de audiências públicas em processos de licenciamento ambiental no estado de Minas Gerais entre 19/07/2018 e 30/11/2019. Fonte: Autores (2020).

A falta da figura da audiência é preocupante, pois pode ser vista como um indicativo de reduzido processo de participação social, que, segundo Quintas (2019), é tão importante por compartilhar poder e responsabilidade sobre as consequências das escolhas no destino da coletividade e por ser capaz de promover a prevenção e a mitigação dos impactos socioambientais decorrentes dos empreendimentos. 
Tabela 1. Situação das consultas públicas para empreendimentos de mineração em Minas Gerais no período de julho de 2018 a novembro de 2019.

\begin{tabular}{|c|c|c|c|c|}
\hline Atividades do Empreendimento & $\begin{array}{c}\text { Empresa } \\
\text { responsável }\end{array}$ & $\begin{array}{c}\text { Município do } \\
\text { empreendimento }\end{array}$ & $\begin{array}{c}\text { Situação da } \\
\text { Audiência }\end{array}$ & Solicitantes \\
\hline $\begin{array}{l}\text { Lavra a céu aberto - Minério de ferro / } \\
\text { unidade de Tratamento de Minerais, } \\
\text { com tratamento a seco }\end{array}$ & $\begin{array}{l}\text { Mineração Nossa } \\
\text { Senhora do Sion } \\
\text { LTDA }\end{array}$ & Santa Bárbara & $\begin{array}{l}\text { Aguardando } \\
\text { Solicitação }\end{array}$ & - \\
\hline $\begin{array}{l}\text { Lavra a céu aberto - Rochas } \\
\text { ornamentais e de revestimento / Pilha de } \\
\text { rejeito/estéril de rochas ornamentais e } \\
\text { de revestimento }\end{array}$ & $\begin{array}{l}\text { Itinga Mineração } \\
\text { LTDA }\end{array}$ & Itinga & $\begin{array}{l}\text { Aguardando } \\
\text { Solicitação }\end{array}$ & - \\
\hline $\begin{array}{l}\text { Lavra a céu aberto - Rochas } \\
\text { ornamentais e de revestimento / Pilha de } \\
\text { rejeito/estéril de rochas ornamentais e } \\
\text { de revestimento }\end{array}$ & $\begin{array}{l}\text { Pedreiras do } \\
\text { Brasil S.A. }\end{array}$ & Dores de Guanhães & $\begin{array}{l}\text { Aguardando } \\
\text { Solicitação }\end{array}$ & - \\
\hline $\begin{array}{l}\text { Disposição de estéril ou de rejeito inerte } \\
\text { e não inerte da mineração (classe II-A e } \\
\text { II-B) em cava de mina, em caráter } \\
\text { temporário ou definitivo, sem } \\
\text { necessidade de construção de } \\
\text { barramento para contenção / Lavra a céu } \\
\text { aberto - Minerais não metálicos, exceto } \\
\text { rochas ornamentais e de revestimento / } \\
\text { Lavra a céu aberto - Minério de ferro / } \\
\text { Pilhas de rejeito/estéril - Minério de } \\
\text { ferro }\end{array}$ & $\begin{array}{l}\text { MML Metais } \\
\text { Mineração } \\
\text { LTDA }\end{array}$ & Passa Tempo & $\begin{array}{l}\text { Aguardando } \\
\text { Solicitação }\end{array}$ & - \\
\hline $\begin{array}{c}\text { Lavra a céu aberto sem tratamento ou } \\
\text { com tratamento a seco - minério de } \\
\text { ferro }\end{array}$ & $\begin{array}{l}\text { VALE S/A - } \\
\text { Complexo } \\
\text { Mariana - Mina } \\
\text { de Fazendão }\end{array}$ & Catas Altas/Mariana & Solicitada & $\begin{array}{c}\text { Entidade } \\
\text { civil; grupo } \\
\text { de } 50 \text { ou mais } \\
\text { cidadãos }\end{array}$ \\
\hline $\begin{array}{l}\text { Lavra a céu aberto - minério de ferro; } \\
\text { unidade de Tratamento de Minerais, } \\
\text { com tratamento a úmido }\end{array}$ & Projeto Bloco 8 & $\begin{array}{l}\text { Fruta de Leite/Grão } \\
\text { Mongol/Josenópolis } \\
\text { / Padre Carvalho }\end{array}$ & Solicitada & $\begin{array}{c}\text { Prefeito; } \\
\text { Entidade civil }\end{array}$ \\
\hline $\begin{array}{l}\text { Extração de areia e cascalho para } \\
\text { utilização imediata na construção civil }\end{array}$ & $\begin{array}{l}\text { Construtora } \\
\text { Quebec S.A. - } \\
\text { PCH Quartel I }\end{array}$ & $\begin{array}{l}\text { Conceição do Mato } \\
\text { Dentro / Gouvêa / } \\
\text { Santana de Pirapema }\end{array}$ & Agendada & Entidade civil \\
\hline $\begin{array}{l}\text { Extração de areia e cascalho para } \\
\text { utilização imediata na construção civil }\end{array}$ & $\begin{array}{l}\text { Construtora } \\
\text { Quebec S.A. - } \\
\text { PCH Quartel II }\end{array}$ & $\begin{array}{l}\text { Conceição do Mato } \\
\text { Dentro / Gouvêa / } \\
\text { Santana de Pirapema }\end{array}$ & Agendada & Entidade civil \\
\hline $\begin{array}{c}\text { Alteamento de barragem de rejeitos, } \\
\text { pilha de estéril e alteração da geometria } \\
\text { da cava }\end{array}$ & AMG Mineração & Nazareno & Realizada & $\begin{array}{c}\text { Prefeito; } \\
\text { Entidade civil }\end{array}$ \\
\hline $\begin{array}{c}\text { Lavra subterrânea, exceto pegmatitos e } \\
\text { gemas }\end{array}$ & $\begin{array}{l}\text { NEXA Recursos } \\
\text { Minerais }\end{array}$ & Paracatu & Realizada & $\begin{array}{c}\text { Próprio } \\
\text { empreendedor }\end{array}$ \\
\hline Lavra a céu aberto - Minério de ferro & $\begin{array}{l}\text { Capital Minera } \\
\text { Investimento } \\
\text { LTDA }\end{array}$ & Guanhães & Realizada & $\begin{array}{l}\text { Secretário } \\
\text { executivo do } \\
\text { COPAM }\end{array}$ \\
\hline $\begin{array}{l}\text { Unidade de Tratamento de Minerais, } \\
\text { com tratamento a úmido }\end{array}$ & $\begin{array}{l}\text { CSN Mineração } \\
\text { S.A. }\end{array}$ & Congonhas & Realizada & $\begin{array}{l}\text { Ministério } \\
\text { Público, } \\
\text { Prefeito }\end{array}$ \\
\hline
\end{tabular}

Fonte: Autores (2020).

O elevado número de casos em que a solicitação de audiência pública foi ausente pode ser justificado, segundo Almeida et al. (2018), por duas razões principais: o fato de o evento ser facultativo no Estado e a falta de envolvimento da sociedade nos processos. Sobre a primeira razão, a audiência pública só ocorre caso algum agente solicite: se a solicitação não for feita por um dos interessados (Ministério Público, entidade civil, empreendedor, prefeito e 50 ou mais cidadãos), o órgão ambiental mineiro muito raramente o faz. Ou seja, existe o entendimento de obrigatoriedade apenas da publicidade para o prazo de convocação da audiência e não da realização da mesma. Com relação à segunda, ainda que seja dada a devida publicidade ao período de solicitação da audiência, 
os autores apontam para um baixo interesse em processos participativos e a frágil cultura de participação predominante no Estado.

Por fim, cabe destacar que esta realidade de não realização de audiência em casos de licenciamento com EIA/RIMA não é vivenciada por todos os órgãos ambientais licenciadores no país, não ocorrendo, por exemplo, em São Paulo (Almeida e Montaño, 2017) e no Espírito Santo (Faria e Silva, 2017), onde a audiência é aplicada a todos os casos.

Uma vez apresentado o panorama geral de realização das audiências em todas as tipologias de atividades, focou-se nos processos de interesse que estão relacionados a empreendimentos minerários. Para esta tipologia de atividade, foram encontrados 12 processos, dos quais: 4 estavam aguardando solicitação de audiência; 2 com este processo participativo já agendado; 2 com solicitação realizada, mas sem agendamento efetuado; e 4 com audiências já realizadas. A Tabela 1 traz a situação das audiências dos processos associados à mineração em 01/12/2019.

Levando-se em consideração que a participação social é apontada pela legislação como devendo ocorrer durante a realização de um processo de licenciamento ambiental com a elaboração do EIA (CONAMA, 1987), sendo necessária para sua legitimidade (Silva et al., 2018), e a sua importância (Sánchez, 2013), faz-se pertinente questionar a falta de interesse em envolver-se em processos participativos em Minas Gerais, uma vez que, considerando todas as tipologias de empreendimentos, $85 \%$ deles não tiveram audiências solicitadas. No entanto, a situação parece ser diferente quando o foco se volta para atividades minerárias: de 12 processos, dois terços já contavam com a figura da audiência, seja ela solicitada, agendada ou já realizada. No terço restante, a audiência ainda pode ocorrer, conforme a solicitação seja ou não efetuada dentro do prazo. Ainda, foi verificado, ao analisar todos os processos do período avaliado, a realização de 6 audiências das quais 4 eram de empreendimentos minerários. Em outras palavras, a participação sob a forma de audiência pública, tão ausente nos processos de licenciamento em Minas Gerais, esteve mais presente quando se tratava de mineração.

A maior realização de audiências públicas em empreendimentos minerários, quando comparado a outros tipos de empreendimentos, poderia ser atribuída à elevada atenção midiática sobre tal setor após o rompimento das barragens de rejeitos em Mariana, em 2015, e Brumadinho, em 2019. Principalmente, porque o período analisado na pesquisa compreende apenas os anos de 2018 e 2019. Uma vez que os impactos ambientais e sociais causados pelos empreendimentos minerários foram amplamente divulgados durante esse período, a possibilidade de ser afetada por tais projetos pode ter aumentado o interesse da população na realização de audiências públicas (Melek et al., 2017; Santos e Borges, 2019) e também pode ter aumentado a cautela dos órgãos públicos.

Assim, faz-se importante também analisar o perfil dos solicitantes das audiências públicas de processos de licenciamento ambiental de atividades minerárias no estado de Minas Gerais, de modo a se evidenciar de quem parte o interesse em participar. O resultado está ilustrado pela Figura 2. Ressalta-se que a audiência pública relativa a um empreendimento pode ter sido solicitada por mais de um órgão ou entidade e que foram considerados os 8 processos onde a audiência foi realizada ou agendada.

Observa-se que as entidades civis sem fins lucrativos realizaram o maior número de solicitações de audiências públicas, requerendo que 5 audiências fossem realizadas e evidenciando a importância dessas entidades na efetivação da participação social no setor ambiental. A participação neste setor é de extrema valia para a justiça social, cujos princípios fornecem um modo de atribuir direitos e deveres nas instituições básicas da sociedade e definem a distribuição apropriada dos benefícios e dos custos da cooperação social (Rawls, 2000).

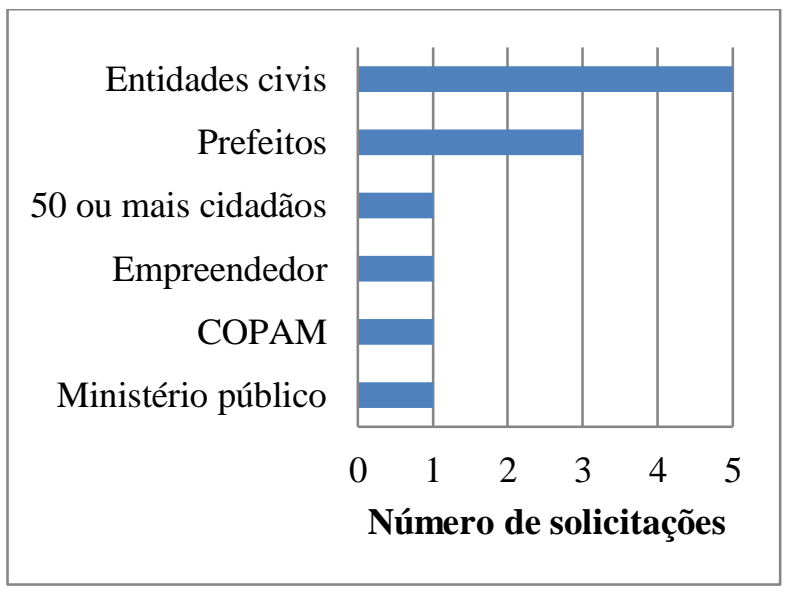

Figura 2. Solicitantes de audiências públicas para empreendimentos minerários em Minas Gerais, em 2018 e 2019. Fonte: Autores (2020).

As prefeituras também se mostraram mais participativas, realizando 3 solicitações durante o período. Isso mostra que a maior preocupação com os riscos associados à mineração ocorreu por parte de entidades civis e de autoridades locais. 
Para descrever a participação social durante as audiências públicas nos processos de licenciamento minerários, foram estudadas as atas dos quatro empreendimentos minerários de Minas Gerais que já realizaram o evento, conforme especificado na Tabela 2. Cabe destacar que o número de atas analisadas é pequeno, mas é o universo de todas as audiências de empreendimentos minerários após a criação do sistema eletrônico de solicitação. As atas foram analisadas com base em alguns pontos considerados relevantes para propiciar a participação da sociedade. Essa análise possibilitou uma visão geral da dinâmica de cada audiência e da extensão da participação social dentro deste evento participativo, que por natureza é consultivo e não deliberativo (CONAMA, 1987). Os resultados encontrados para cada audiência, de acordo com os pontos pré-estabelecidos, se encontram sintetizados na Tabela 3. Os tópicos seguintes trazem uma análise detalhada dessas informações.

Tabela 2. Atas de audiências públicas de processos de licenciamento de mineração analisadas.

\begin{tabular}{cccc}
\hline $\begin{array}{c}\text { Empresa } \\
\text { Responsável }\end{array}$ & Município & $\begin{array}{c}\text { Data de realização } \\
\text { da audiência }\end{array}$ & Ata disponível em: \\
\hline AMG Mineração & Nazareno & $\begin{array}{c}21 / 11 / 2018 \text { (quarta- } \\
\text { feira) }\end{array}$ & $\begin{array}{c}\text { http://sistemas.meioambiente.mg.gov.br/licenciamento/ata/k } \\
\text { 01TUKDyuUJ13H8snJIMLGxfycizSANe.pdf }\end{array}$ \\
\hline $\begin{array}{c}\text { CSN Mineração } \\
\text { S. A. }\end{array}$ & Congonhas & $\begin{array}{c}08 / 01 / 2019 \text { (quinta- } \\
\text { feira) }\end{array}$ & $\begin{array}{c}\text { http://sistemas.meioambiente.mg.gov.br/licenciamento/ata/ } \\
\text { Z6SLO_v2CFjJKIn6T4uw-H5dV4hhCY6q.pdf }\end{array}$ \\
\hline $\begin{array}{c}\text { NEXA Recursos } \\
\text { Minerais S. A. }\end{array}$ & Paracatu & $\begin{array}{c}23 / 04 / 2019 \\
\text { (sábado) }\end{array}$ & $\begin{array}{c}\text { http://sistemas.meioambiente.mg.gov.br/licenciamento/ata/ } \\
\text { wZ1icO84_owCS18PRMAYNbG2IK3xoRZl.pdf }\end{array}$ \\
\hline $\begin{array}{c}\text { Capital Minera } \\
\text { Investimentos } \\
\text { LTDA }\end{array}$ & Guanhães & $\begin{array}{c}21 / 05 / 2019 \\
\text { (terça-feira) }\end{array}$ & $\underline{\text { http://sistemas.meioambiente.mg.gov.br/licenciamento/ata/ }}$ \\
\hline
\end{tabular}

Fonte: Autores (2020).

\section{Horários e locais da audiência pública}

Segundo Mencio et al. (2005), audiências públicas precisam garantir a maior representatividade possível da população; portanto, as datas, horários e locais devem ser favoráveis a participação dos indivíduos interessados, não as realizando, por exemplo, durante a tarde ou em feriados. Recomenda-se que tais eventos aconteçam em locais de fácil acesso e em horários que não prejudiquem a vida cotidiana da comunidade, priorizando o período noturno, não muito tardio, e finais de semana.

Quanto ao horário e local, as audiências dos quatro empreendimentos se mostraram favoráveis à participação social (pontos positivos para propiciar a participação), uma vez que ocorreram à noite, fora do horário comercial, em datas oportunas, em locais amplos e acessíveis à população.

\section{Linguagem e forma de apresentação do projeto $e$ impactos}

Considerando que audiências públicas são processos dispendiosos e podem ocasionar o desvirtuamento de informações (Gomes e Teixeira, 2017), há de se considerar a linguagem utilizada na apresentação das informações como indicativo de favorecimento ou não da participação em uma audiência pública. Sánchez (2013) recomenda o uso de termos simplificados e mais acessíveis, uma vez que grande parte do público presente no evento não tem condições de compreender expressões de cunho técnico.

A audiência pública organizada pela NEXA Recursos Minerais S. A. se mostrou falha quanto à linguagem utilizada, uma vez que o consultor responsável pela apresentação do projeto empregou termos estritamente científicos em sua fala, de difícil compreensão por parte de um público leigo, como pode ser observado nos seguintes excertos, retirados da ata da audiência pública:

“(...) o principal objetivo nessa caracterização é nós identificarmos onde há um potencial espeleológico, porque em ambiente de rochas carbonáticas há uma susceptibilidade no desenvolvimento dessas cavidades." (Consultor).

“(...) Onde há ocorrência de mineralizações de sulfeto, esses que é o objeto de exploração para posteriormente beneficiamento das substâncias pleiteadas nesse projeto, que é o caso do zinco e chumbo. Esse material em contato com o ambiente, ele pode promover uma oxidação, uma solubilização e acelerar um processo chamado de drenagem ácida." (Consultor). 
“(...) Estudos de ictiofauna e organismos aquáticos e além dos mamíferos voadores, que são os morcegos. Também foram estudados e não estão representados aqui, os estudos de entomoufauna, ou seja, nenhum grupo faunístico ficou de fora. Destaque para todos esses grupos, no grupo de mastofauna e de aves que apresentaram espécies, em alguma listagem ameaçada de extinção." (Consultor).
A linguagem aplicada na audiência pública da AMG Mineração variou conforme o ator. Enquanto o engenheiro responsável pelo projeto do empreendimento comunicou-se de maneira complexa e rebuscada, a geóloga, encarregada da coordenação dos estudos ambientais, buscou se expressar de maneira didática e acessível. Os trechos a seguir, retirados da ata da audiência pública, revelam esse contraste:

Tabela 3. Informações sobre as audiências públicas realizadas no licenciamento ambiental de empreendimentos minerários em Minas Gerais entre 2018 e 2019.

\begin{tabular}{|c|c|c|c|c|}
\hline Empreendimento & $\begin{array}{c}\text { AMG } \\
\text { MINERAÇÃO }\end{array}$ & $\begin{array}{l}\text { CSN Mineração } \\
\text { S.A. }\end{array}$ & $\begin{array}{c}\text { NEXA Recursos } \\
\text { Minerais S.A. }\end{array}$ & $\begin{array}{c}\text { Capital Minera } \\
\text { Investimentos LTDA }\end{array}$ \\
\hline $\begin{array}{c}\text { Horário da } \\
\text { audiência }\end{array}$ & $19: 00$ & $18: 30$ & $19: 00$ & $18: 00$ \\
\hline Local da audiência & Quadra do Rosário & $\begin{array}{c}\text { Ginásio } \\
\text { poliesportivo José } \\
\text { Juracélio de } \\
\text { Santana } \\
\end{array}$ & $\begin{array}{l}\text { Loja Maçônica } \\
\text { Nova Luz } \\
\text { Paracatuense }\end{array}$ & $\begin{array}{c}\text { Câmara Municipal de } \\
\text { Guanhães }\end{array}$ \\
\hline $\begin{array}{c}\text { Linguagem } \\
\text { utilizada e forma } \\
\text { de apresentação do } \\
\text { projeto e impactos }\end{array}$ & $\begin{array}{l}\text { Caráter técnico, } \\
\text { com foco na } \\
\text { resolução de } \\
\text { problemas pontuais } \\
\text { e individuais dos } \\
\text { manifestantes. }\end{array}$ & $\begin{array}{l}\text { O empreendedor } \\
\text { utiliza uma } \\
\text { linguagem de } \\
\text { caráter comercial } \\
\text { enquanto o } \\
\text { representante da } \\
\text { consultoria } \\
\text { responsável pelo } \\
\text { EIA/RIMA } \\
\text { apresentou o } \\
\text { projeto de forma } \\
\text { mais acessível. } \\
\text { Entretanto, os } \\
\text { impactos negativos } \\
\text { não foram } \\
\text { aprofundados na } \\
\text { fala do consultor, } \\
\text { dando maior } \\
\text { atenção às } \\
\text { ferramentas de } \\
\text { monitoramento e } \\
\text { mitigação. }\end{array}$ & $\begin{array}{l}\text { Caráter técnico e } \\
\text { comercial durante a } \\
\text { explanação do } \\
\text { projeto, com foco } \\
\text { nos benefícios e } \\
\text { alternativas. A } \\
\text { abordagem de } \\
\text { riscos e prejuízos } \\
\text { foi bastante } \\
\text { superficial. }\end{array}$ & $\begin{array}{c}\text { Apresentação clara e } \\
\text { com linguagem } \\
\text { acessível, com foco nos } \\
\text { impactos } \\
\text { socioeconômicos } \\
\text { positivos e abordagem } \\
\text { dos impactos físicos } \\
\text { reversíveis e passíveis } \\
\text { de } \\
\text { controle/monitoramento. }\end{array}$ \\
\hline $\begin{array}{c}\text { Tempo de fala dos } \\
\text { manifestantes }\end{array}$ & $\begin{array}{c}3 \text { minutos por } \\
\text { manifestante (12 } \\
\text { blocos de } 3 \\
\text { perguntas de } 3 \\
\text { minutos cada uma) } \\
\text { e resposta de } 6 \\
\text { minutos. }\end{array}$ & $\begin{array}{c}3 \text { minutos por } \\
\text { manifestante (12 } \\
\text { blocos de } 3 \\
\text { perguntas de } 3 \\
\text { minutos cada uma) } \\
\text { e resposta de } 6 \\
\text { minutos. }\end{array}$ & $\begin{array}{c}3 \text { minutos por } \\
\text { manifestante }(12 \\
\text { blocos de } 3 \\
\text { perguntas de } 3 \\
\text { minutos cada uma) } \\
\text { e resposta de } 6 \\
\text { minutos. }\end{array}$ & $\begin{array}{c}3 \text { minutos por } \\
\text { manifestante ( } 12 \text { blocos } \\
\text { de } 3 \text { perguntas de } 3 \\
\text { minutos cada uma) e } \\
\text { resposta de } 6 \text { minutos. }\end{array}$ \\
\hline $\begin{array}{l}\text { Presença de } \\
\text { lideranças } \\
\text { comunitárias }\end{array}$ & $\begin{array}{l}\text { Sim (moradores do } \\
\text { município, } \\
\text { representantes de } \\
\text { associações, } \\
\text { empresas, escolas e } \\
\text { instituições). }\end{array}$ & $\begin{array}{c}\text { Sim (representantes } \\
\text { de conselhos, } \\
\text { associações e } \\
\text { vereadores). }\end{array}$ & $\begin{array}{l}\text { Ata incompleta (não } \\
\text { há relato de } \\
\text { pronunciamentos do } \\
\text { público, apenas dos } \\
\text { representantes do } \\
\text { empreendimento e } \\
\text { da consultoria } \\
\text { responsável pelo } \\
\text { EIA/RIMA. }\end{array}$ & $\begin{array}{c}\text { Sim (representante da } \\
\text { Federação dos } \\
\text { Trabalhadores nas } \\
\text { Indústrias Extrativas do } \\
\text { Estado de Minas } \\
\text { Gerais). }\end{array}$ \\
\hline
\end{tabular}




\begin{tabular}{ccccc}
\hline $\begin{array}{c}\text { Presença de } \\
\text { membros } \\
\text { independentes da } \\
\text { sociedade civil }\end{array}$ & $\begin{array}{c}\text { Sim (moradores do } \\
\text { município e } \\
\text { funcionário da } \\
\text { empresa - setor de } \\
\text { manutenção } \\
\text { industrial). }\end{array}$ & $\begin{array}{c}\text { Sim (moradores do } \\
\text { município e do } \\
\text { município vizinho). }\end{array}$ & $\begin{array}{c}\text { Ata incompleta (não } \\
\text { há relato de } \\
\text { pronunciamentos do } \\
\text { público, apenas dos } \\
\text { representantes do } \\
\text { empreendimento e } \\
\text { da consultoria } \\
\text { responsável pelo } \\
\text { EIA/RIMA). }\end{array}$ & $\begin{array}{c}\text { Sim (moradores do } \\
\text { município e de } \\
\text { municípios vizinhos, } \\
\text { empreendedores locais e } \\
\text { trabalhadores da Capital } \\
\text { Mineração). }\end{array}$ \\
\hline $\begin{array}{c}\text { Fornecimento de } \\
\text { transporte para a } \\
\text { audiência pública }\end{array}$ & Sim & Não informado & Sim & Não informado \\
\hline Lista de presença & Sim (32 presentes) & Não informado & Sim (21 presentes) & Sim (173 presentes) \\
\hline & & Fonte: Autores (2020). & \\
\hline
\end{tabular}

“(...) eu volto agora pra separação magnética, onde nós conseguimos nessa etapa, já deixar em fase final de processo concentrado de cassiterita, o concentrado de tantalita (...). A próxima etapa, que é uma etapa de desenvolvimento, a gente retira essa areia que fica espalhada ao redor da AMG Mineração. A gente concentra ela através de ferro e produzimos o feldspato (...). E, recentemente, a gente inaugurou uma planta de concentração

espodumênio(...).”(Engenheiro).

“(...) o estudo ambiental, ele se baseia no estudo do meio físico, biótico e socioeconômico. $\mathrm{Na}$ definição das áreas de influência, são basicamente três áreas: é a ADA, que é a área diretamente afetada, que é composta exatamente pela área que vai ocupar o empreendimento. Posteriormente vem a área de influência direta, que é o entorno mais próximo, que vai estar sujeito aos impactos diretamente. E a área de influência indireta, que vai sofrer indiretamente os impactos. No caso do meio físico e biológico, (...) a gente define essas áreas pelas bacias hidrográficas da região, os cursos d'água (...). Para o meio socioeconômico, (...) AID, essa é composta pelas comunidades diretas ali no entorno (...)" (Geóloga).

O representante da consultoria responsável pelo EIA/RIMA da CSN Mineração S.A. se mostrou mais cuidadoso quanto à linguagem e se pronunciou de forma mais compreensível quanto aos impactos do projeto e respectivas ferramentas de mitigação. Entretanto, observa-se nos trechos a seguir, retirados da ata da audiência, que os aspectos foram apresentados superficialmente, gerando margem para inconsistências na interpretação, principalmente, de modo a amenizar os impactos negativos.

"Quanto aos impactos negativos tanto na fase de operação quanto implantação para o meio biótico, nós estamos falando que vamos ocupar uma área que tem vegetação,(...) então é muito mais pela supressão vegetal e pela perda de habitats, que são observados esses impactos na fauna e a flora. Para o meio físico essas alterações, esses impactos que nós observamos estão ligados a qualidade do ar, ruído, dinâmica dos rios, (...) qualidade das águas, disponibilidade de solo (...)." (Consultor).

“(...) nós estamos falando que deve ter um projeto de educação ambiental, sinalização de vias de acesso, sistemas de drenagem adequados, programa de resgate de fauna e da flora, acompanhamento das atividades de supressão da flora, monitorar essa fauna, monitorar a qualidade da água superficial e fazer programa de recuperação das áreas degradadas." (Consultor).

No caso da Capital Minera Investimentos LTDA, os consultores se mostraram mais responsáveis quanto à linguagem e se pronunciaram de forma mais compreensível a respeito dos elementos do projeto. Os aspectos positivos são bastante enfatizados e os aspectos negativos foram logo rebatidos por propostas de mitigação e controle. A seguir estão transcritos alguns trechos relevantes das atas da audiência, que corroboram com as afirmações anteriores:

\begin{tabular}{|l|}
\hline "Eu vou começar apresentando os impactos no \\
meio socioeconômico. O primeiro impacto que \\
vemos é a alteração do nível de emprego durante \\
as fases de implantação, operação e fechamento \\
da mina (...). A magnitude dele é baixa ou média, \\
a duração desse impacto é permanente, e ele é \\
considerado de baixa importância ou importante. \\
Outro impacto é a alteração no nível de \\
formalização das relações trabalhistas. Como eu \\
falei com vocês, (...) eu creio que muda muito o \\
quadro dessas pessoas que estão empregadas, em \\
uma época tão complicada de se conseguir \\
emprego, e também de suas famílias, seus
\end{tabular}

Alves.G. P., Marcondes. A. L. S, Bucci., M. E. D. Almeida. M. R. R. 
dependentes diretos, além de injetar um dinheiro no comércio de Guanhães e movimentar toda a economia nessa escala municipal." (Gerente de sustentabilidade)

"Em relação à qualidade do ar, a natureza é negativa, mas esse impacto é reversível e é controlável também, a duração dele é temporária, a magnitude é baixa ou média durante a operação da mina. De onde vem esse impacto de alteração da qualidade do ar? Movimentação de máquinas, movimentação de caminhões. O que a Capital Mineração faz para controlar esse desconforto na qualidade do ar? Nós temos um programa de controle de emissão de material particulado(...)" (Gerente de sustentabilidade).

Bullard (1994) afirma que empreendedores e parceiros são capazes de criar articulações que traçam o imaginário de desenvolvimento e progresso para o público, mostrando o empreendimento como solução para os problemas locais e regionais, e realçando benefícios para todos os setores, com ênfase no incremento econômico, a partir da apresentação de dados concretos a respeito do desemprego. Ficou evidente que as empresas usam de artifício semelhante, partindo do princípio da dependência do município perante a atividade: as falas dos empreendedores enfatizam a importância do empreendimento na geração de empregos na cidade e na contribuição para o giro da economia. Tal fato pode ser considerado uma forma de manipulação da comunidade local, que se vê obrigada a aceitar riscos potenciais por conta da dependência da empresa (Milanez, 2014; Coelho, 2015). Neste contexto, reforça-se que a participação só é livre e igualitária se forem livres as suas condições efetivas, o que na sociedade instituída não ocorre efetivamente (Vasconcelos, 1985). Destaca-se, ainda, em todos os casos, a exploração superficial dada aos riscos, prejuízos e impactos ambientais negativos que a instalação e operação das organizações minerárias podem trazer ao local. Esses fatores parecem ser ainda mais minimizados ao precederam a apresentação das ferramentas de monitoramento e mitigação, que são amplamente exaltadas pelo enunciador.

\section{Tempo de fala dos manifestantes}

A Deliberação Normativa do COPAM $\mathrm{n}^{\circ}$ 225/2018 estabelece em seu art. 15 inciso III "cada bloco é composto por três falas ou questões dos presentes, sendo cada um de até três minutos, seguidas de resposta única de até seis minutos do empreendedor" (COPAM, 2018).
Foi verificado que todos os processos analisados atenderam ao regramento legal especificado para este fator. No entanto, torna-se pertinente avaliar se o cumprimento da legislação é suficiente para que o processo seja efetivamente participativo. Neste sentido, o Ministério Público do Estado de São Paulo (MPSP) recomenda que a ordem e o tempo de fala sejam condizentes às características culturais dos indivíduos para assim estimular sua participação, sob o risco de se frustrar o objetivo da audiência pública (MPSP, 2016). Logo, a padronização trazida pela legislação, visando à igualdade do tempo de fala, desconsidera fatores socioculturais peculiares a cada localidade e pode não ser razoável para tornar o ambiente apto à plena participação.

Lista de presença e participação de lideranças comunitárias e de membros independentes da sociedade civil

Conforme previsto pela Deliberação Normativa do COPAM n ${ }^{\circ} 225 / 2018$, a lista de presença, o relatório-síntese da audiência pública, o áudio e outros mecanismos de registro são utilizados na validação do evento e são considerados na avaliação pertinente ao pedido de licença (COPAM, 2018). Foi observado que, em três dos empreendimentos, houve a disponibilização do registro em lista dos presentes na audiência pública realizada, a AMG Mineração, a NEXA Recursos Minerais S.A e a Capital Minera Investimentos LTDA. Cumpre-se, dessa forma, nestes casos, o que está previsto na legislação, porém não há garantia, a partir disso, de plena participação social no processo.

A presença de lideranças comunitárias e de membros independentes da sociedade civil ocupa papel fundamental para a efetividade da participação social (Wampler, 2011). Nos casos em estudo, foi verificado que nas audiências da AMG Mineração, CSN Mineração S.A. e Capital Minera Investimentos LTDA houve a participação de tais membros. No entanto, a ata da audiência da NEXA Recursos Minerais S.A. foi a única dentre as estudadas que não apresentou relato do pronunciamento do público, estando incompleta e apenas havia a lista de presença que apontava para 21 presentes.

No caso da Nexa, mesmo sem saber do número de manifestantes e das suas considerações, é possível tentar estabelecer algumas relações. O baixo número de presentes no evento (menor entre as informações avaliadas) pode ter relação com o solicitante da audiência, que foi o próprio empreendedor, e com as características da própria atividade (Lavra subterrânea, exceto pegmatitos e 
gemas), revelando provavelmente que o projeto não despertou o interesse da população.

A audiência pública da AMG Mineração contou com a fala de 31 membros da sociedade civil, dentre eles moradores do município e representantes de associações, de escolas, de indústrias e de instituições. Como 32 pessoas assinaram a lista de presença, praticamente todos os presentes se manifestaram. Apesar de alguns apontamentos serem de ordem pessoal, como rachaduras e excesso de poeira na propriedade do enunciador, a maioria das discussões ocorreram em torno de problemáticas coletivas, como: reivindicação de saúde, educação e emprego para a população; segurança de barragem; acessibilidade e manutenção das vias impactadas pelo trânsito de máquinas e automóveis da empresa; ruídos na comunicação entre a mineradora e a sociedade; responsabilidade social empresarial; e questões ambientais, como a poluição dos corpos hídricos, qualidade da água do município e a exigência de práticas concretas para o desenvolvimento sustentável local. Ainda, foram relatados pronunciamentos abertamente favoráveis ao empreendimento, livres de críticas à atividade geradora de impacto socioambiental, fundamentados na importância econômica da mineradora para a região. Em resumo e analisando o contex to como um todo desta audiência, percebese que ela não contou com grande número de participantes, mas que quase a totalidade se manifestou (também é o maior número de manifestantes das atas analisadas) e se mostrou preocupada com os riscos e questões ambientais do empreendimento. Ou seja, parece ter sido um espaço de discussão sobre o empreendimento, seus impactos e riscos e sua interferência na comunidade. A intensa manifestação no evento pode estar relacionada à sua tipologia (alteamento de barragem de rejeitos, pilha de estéril e alteração da geometria da cava), já que representa a mesma dos desastres de Mariana e Brumadinho, e que o prefeito e a entidade civil foram porta vozes das preocupações dos afetados ao solicitarem a realização da audiência.

Já a audiência da Capital Mineração teve 173 participantes com 18 inscritos para manifestações. Dentre os falantes, foram encontrados moradores, vereadores, presidente de sindicato e liderança comunitária. Apesar de haver alguns posicionamentos contrários em relação à implementação do empreendimento em Guanhães/MG, houve muitos posicionamentos favoráveis devido ao progresso que o empreendimento poderia trazer. Os assuntos mais abordados foram: danos ao meio ambiente e à sociedade; retorno dos lucros da empresa para melhorias no município; progresso social devido à geração de trabalho e riquezas; meios para incentivar a implantação de empreendimentos no município; licença ambiental e comprometimento da empresa para com a comunidade; iniciativa público-privada; melhorias nas condições de trabalho dos trabalhadores; minimização dos impactos ambientais; impacto do transporte nas vias do município e o Serviço de Atendimento ao Consumidor criado pela empresa para atender a população em geral. Em síntese, a audiência, solicitada pelo Secretário executivo do COPAM, contou com a maior presença das atas analisadas, mas com a manifestação de, aproximadamente, $10 \%$ dos presentes. Os debates foram mais voltados aos benefícios do empreendimento e do comprometimento do mesmo com a comunidade. Pode ser que as discussões tenham tomado este rumo porque o objeto do licenciamento era apenas a lavra a céu aberto de minério de ferro.

A audiência realizada pela CSN Mineração teve a participação de 25 manifestantes (como não foi disponibilizada a lista de presença, não foi possível saber ao todo quantas pessoas estavam presentes). Além de críticas aos danos ao meio ambiente, também foram encontradas pontuações positivas referentes ao desenvolvimento e a geração de empregos ocasionados pela obra. No entanto, tiveram alguns questionamentos específicos, como, por exemplo, a falta de segurança em creches e escolas inativas por estarem localizadas em áreas de risco; melhorias de bairros desvalorizados localizados próximos à barragem; melhoria de direitos trabalhistas, condições de trabalhos e segurança dos empregados; existência de um canal de comunicação da empresa com candidatos a empregos; soluções da empresa para problemas relacionados aos recursos hídricos utilizados e o material particulado gerado; datas de início e tempo de duração do projeto; capacitação da comunidade residente em Congonhas; funcionamento do sistema de alarmes e segurança da barragem; aumento da produção e alteração na vida útil da mina; reaproveitamento e disposição final de rejeitos; existência de supressão vegetal e localização da área de compensação e, por fim, impactos geográficos na cidade vizinha e soluções alternativas para disposição de rejeitos. A solicitação da audiência por parte do ministério público e do prefeito, provavelmente, já era um indicativo de interesse de participação, refletido nos 25 manifestantes, e dos conflitos apontados nas questões abordadas que estão associadas ao tipo de empreendimento (Unidade de Tratamento de Minerais, com tratamento a úmido). 
Nota-se que, em comum, a maioria das pontuações, tanto positivas quanto negativas, é atrelada ao caráter e aos riscos ambiental, social e econômico dos empreendimentos. São estes aspectos pertinentes à discussão em torno do licenciamento de uma mineradora e evidenciam a preocupação coletiva da sociedade com relação à instalação de um empreendimento de tal natureza e o conhecimento, mesmo que fundamental, dos assuntos abordados em audiência pública. Logo, nestes casos analisados, apesar de não estar sendo avaliado o alcance da participação na tomada de decisão, a audiência se mostrou como um espaço de discussão sobre temáticas pertinentes e relevantes no contexto da atividade de mineração.

\section{Fornecimento de transporte para a audiência pública}

De acordo com a Deliberação Normativa do COPAM n 225/2018, o empreendedor deverá providenciar transporte para as comunidades afetadas pelo seu empreendimento até o local de realização da audiência pública, caso o município não disponha de transporte público ou se o local escolhido não for atendido por tal serviço (COPAM, 2018). A partir dos dados obtidos nesta pesquisa, não é possível afirmar se os locais definidos para a realização das audiências públicas são abrangidos pelo transporte público. Ainda assim, vale ressaltar que, segundo informações da ata, a AMG Mineração e NEXA Recursos Minerais S. A. ofereceram transporte para o local, o que pode ter facilitado o deslocamento e a participação dos interessados, enquanto que nas atas referentes às audiências da Capital Minera Investimentos LTDA e da CSN Mineração S. A. não há informações a respeito da disponibilidade de transporte. No entanto, conforme estudo de caso realizado por Lerner et al. (2016), a disponibilidade de transporte para condução até o local da audiência pública não é suficiente para uma participação representativa. Ainda que a legislação seja cumprida, é assertiva à participação uma divulgação ampla do evento e de informações referentes a ele, assim como a facilitação de acesso.

Finalizando a análise dos resultados, é importante destacar que o presente estudo levantou informações relevantes sobre se ocorrem e como ocorreram as audiências públicas nos empreendimentos minerários em Minas Gerais, apontando pontos favoráveis e desfavoráveis à participação, sem, no entanto, avaliar a efetividade desta participação social. Assim, os dados aqui apresentados podem substanciar estudos futuros, uma vez que existem outras adversidades de ordem prática que interferem na participação efetiva dos cidadãos em audiências públicas, com destaque ao tempo que deve ser dedicado ao comparecimento no evento, a leitura do EIA/RIMA e o espaço de fala dentro da audiência pública (Sánchez, 2013), entre tantos outros.

Convêm ainda alertar para o fato de que ouvir aos participantes nessas audiências não significa de modo algum que suas falas e reivindicações serão levadas em consideração nos processos decisórios. A própria experiência tem mostrado que, na prática, as audiências públicas presentes nos processos de licenciamento de empreendimentos mineradores não são tão democráticas quanto deveriam: elas, muitas vezes, se resumem a uma etapa burocrática para garantia de licenças ou acabam sendo organizadas pelo Poder Público de forma tendenciosa e em favor da empresa (Giffoni et al., 2019). Lopes e Oliveira (2018) alegam, ainda, que a política mineral brasileira tem favorecido interesses privados em detrimento do interesse público, tornando a participação social, quando existente, meramente figurativa. Contribui para isso a existência de anseios particulares, que buscam impedir que a população conheça seus diretos e os exija, a falta de informação disponível e a sua dificuldade de acesso (Rolim et al., 2013).

$\mathrm{O}$ desenvolvimento de sujeitos mais sensíveis requer a construção de processos sociais emancipatórios (Santos, 2018), o que, por sua vez, de acordo com Loureiro (2007), requer um arranjo social que assegure iguais condições de participação e de decisão aos diferentes atores sociais que são partícipes desse processo, no qual as relações de produção se darão de forma justa. No entanto, cabe destacar que sobre a perspectiva dominante de desenvolvimento da humanidade, o capitalismo, como o sistema econômico, social e político, se configura, estruturalmente, à base de relações de desigualdade por meio da exploração do trabalho e controle absoluto de bens naturais vitais do planeta Terra (Prestes, 2019). Ainda, no modo de sociabilidade capitalista, as políticas públicas sempre terão um caráter de classe, sendo determinadas pelos interesses do capital (Lessa, 2013). Assim, a contradição entre capital e natureza excede as ferramentas tradicionais de gestão e ação e o crescimento exponencial infinito da economia capitalista é contradição do capital, enquanto processo necessário para efetivar a promessa de universalização do bem estar (Harvey, 2016).

\section{Considerações Finais}

Diversos estudos apontam a necessidade da participação social nos processos de licenciamento ambiental. Ressalta-se que tal participação só é possível com a existência de um 
processo recorrente de educação ambiental da comunidade, de modo que os indivíduos estejam cientes da importância de exercer seu direito como contestadores de possíveis atos falhos e irresponsáveis, sejam capazes de trocar informações, sanar dúvidas e apresentar comentários pertinentes com relação ao projeto. Para que se concretize, é dever do Poder Público promover espaços adequados para participação social, nos quais haja a liberdade de expressão e a transmissão de informações de forma clara e acessível para toda a comunidade.

Destaca-se que, quando considerada todas as tipologias de empreendimentos, a participação pública em Minas Gerais sob a forma de audiência se mostrou relativamente pequena, sendo que em 85\% de um universo de 143 empreendimentos não houve solicitação. É importante ressaltar a necessidade de estudos que identifiquem o motivo dessa precariedade para que, assim, seja possível identificar metodologias consistentes que promovam a participação da população em assuntos que lhe dizem respeito e cujos resultados podem afetar diretamente seu modo de vida.

Ao se tratar especificamente dos processos referentes a empreendimentos minerários em Minas Gerais, notou-se que, dos 12 casos, 8 contaram com a solicitação de audiências públicas e, destes, 4 já haviam sido realizadas; os demais processos estavam em período de solicitação corrente, considerando-se o intervalo de julho de 2018 a novembro de 2019. Visualiza-se, a partir desses números, um interesse mais considerável na realização de audiências públicas no que se refere à instalação e operação de empreendimentos minerários. Pode-se levantar-se como hipótese de justificativa para tal fato a grande interferência e as apreensões que empreendimentos desta tipologia podem causar às comunidades e municípios envolvidos, principalmente, após os desastres de Mariana e Brumadinho.

Quanto às 4 audiências públicas que já haviam sido realizadas no período, os discursos transcritos nas atas possibilitaram a identificação da dependência dos cidadãos diante das atividades realizadas por mineradoras. Nesse sentido, faz-se necessário repensar a economia local, de modo que as comunidades não sejam subordinadas a empreendimentos geradores de impactos tão significativos com a justificativa apenas de geração de emprego e crescimento do mercado.

Com relação aos fatores prévios à realização da audiência, destaca-se que todas foram realizadas em horários e locais favoráveis à presença da população local, sendo que duas delas contaram com o fornecimento de transporte por parte do empreendedor, facilitando o deslocamento dos interessados até o local de realização da audiência.

A presença de lideranças comunitárias e membros independentes da sociedade civil também se mostrou importante, promovendo a discussão de temáticas pertinentes, e com tempo de fala dos manifestantes de acordo com o regramento legal. Ainda, três das audiências contavam com lista de presença, seguindo também o regramento legal.

$\mathrm{O}$ presente artigo, mais que qualquer coisa buscou apenas descrever a audiência pública sem qualquer análise mais aprofundada sobre seu uso como estratégia efetiva de participação popular. Pelo contrário, os resultados do artigo mostram que nem sob a forma de audiência a participação tem estado presente na maioria dos processos de licenciamento ambiental em Minas Gerais, nem que seja apenas como forma de informar a população sobre o projeto e seus impactos. Ainda, a escolha por avaliar apenas dados do sistema de "Consulta e Requerimento de Audiência Pública", além da facilidade de acesso a informações organizadas, veio com o intuito de verificar se o fato de existir um sistema mais rápido e fácil de solicitação de audiência aumentaria o número de pedidos de realização de audiência, o que não ocorreu pelo baixo número de solicitações encontrado e pela comparação com trabalhos já realizados anteriormente. Por fim, este trabalho faz sentido apenas no contexto de órgãos licenciadores que facultam a realização de audiência em casos de EIA/RIMA. Isso não é visto em outros estados como, por exemplo, São Paulo e Espírito Santo, onde toda vez que o processo de Licenciamento tem EIA/RIMA a audiência vai ocorrer. Por fim, embora existam limitações na pesquisa desenvolvida, uma vez que somente as informações do sistema e das atas das audiências públicas realizadas foram exploradas, restringindo a análise aos dados presentes nesses documentos, este estudo destaca que não realizar audiência indica uma fragilidade de um processo que deveria ser participativo, porém, sua realização não é garantia de efetiva participação .

\section{Referências}

Almeida, M. R. R.; Montaño, M. 2015. Benchmarking na Avaliação de Impacto Ambiental: o sistema mineiro frente às melhores práticas internacionais. Sociedade \& Natureza, 27(1), 81-96. doi: https://doi.org/10.1590/1982-451320150106

Almeida, M. R. R.; Gonçalves, P. V. S.; Farias, C. P. 2018. Participação Pública nos Processos de Licenciamento Ambiental no Triângulo Mineiro. Revista Brasileira de Geografia Física, 
11(2), 510-520. doi: https://doi.org/10.26848/rbgf.v11.2.p510-520

Almeida, M. R. R.; Malvestio, A. C.; Bernadi, Y. R. 2019. Modificações do licenciamento ambiental em Minas Gerais: avanço ou retrocesso? Desenvolvimento e Meio Ambiente, 52, 91-113. doi: http://dx.doi.org/10.5380/dma.v52i0.66068

Bolea, M. E. 1984. Evaluación de impacto ambiental. Madrid: Fundación MAFPRE.

Bullard, R. D. 1994. Dumping in Dixie: race, class and environmental quality. Boulder: Westview Press.

Burian, P. P. 2006. Do estudo de impacto ambiental à avaliação ambiental estratégica: ambivalências do processo de licenciamento ambiental do setor elétrico. 2006. 223 p. Tese (Doutorado em Ciências Sociais) Universidade Estadual de Campinas, Instituto de Filosofia e Ciências Humanas. Campinas.

Carvalho, A. M. P.; Milanez, B.; Guerra, E. C. 2018. Rentismo-neoextrativismo: a inserção dependente do Brasil nos percursos do capitalismo mundializado (1990-2017). In: Rigotto, R. M; Aguiar, A. C. P; Ribeiro, L. A. D. (Orgs.). Tramas para a justiça ambiental: diálogo de saberes e práxis emancipatórias. Fortaleza: Edições UFC, p. 19-57.

Coelho, T. P. Impactos e mineração da Vale em Parauapebas. 2015. In: Barros, J.; Gutterres, A.; Silva, E. B. da (Orgs.). BRICS: tensões do desenvolvimento e impactos socioambientais. Rio de Janeiro: Fase Solidariedade e Educação, p. 47-64. Disponível: http://www.global.org.br/wpcontent/uploads/2016/03/Caderno_Debates4_w eb.pdf\#page=49. Acesso: 04 nov. 2019.

CONAMA - Conselho Nacional do Meio Ambiente. 1986. Resolução ${ }^{\circ} 001$ de 23 de janeiro de 1986. Brasília: DOU de 17/02/1986.

CONAMA - Conselho Nacional do Meio Ambiente. 1987. Resolução $\mathrm{n}^{\circ} 009$ de 03 de dezembro de 1987. Brasília: DOU de 05/07/1990.

COPAM - Conselho Estadual de Política Ambiental (Minas Gerais). 1994. Deliberação Normativa ${ }^{\circ} 12$ de 13/12/1994. Minas Gerais, 23 dez. 1994.

COPAM - Conselho Estadual de Política Ambiental (Minas Gerais). 2017. Deliberação Normativa $\mathrm{n}^{\mathrm{o}} 217$ de 06/12/2017. Minas Gerais, 08 dez. 2017.

COPAM - Conselho Estadual de Política Ambiental (Minas Gerais). 2018. Deliberação Normativa $n^{\circ} 225$ de 25/07/2018. Minas Gerais, 01 ago. 2018.
Faria, G. C.; Silva, F. M. 2017. Participação pública no processo de avaliação de impacto ambiental no Estado do Espírito Santo. Desenvolvimento e Meio Ambiente, 43, 139151. doi: http://dx.doi.org/10.5380/dma.v43i0.54188

Giffoni, R.; Coelho, T.; Maia, M. 2019. A mineração vem aí... E agora? Um guia prático em defesa dos territórios. Rio de Janeiro: Fase | Poemas. Disponível: https://fase.org.br/wpcontent/uploads/2019/08/Aminera\%C3\%A7\%C3\%A3o-vema\%C3\%AD.-E-agora_Web.pdf. Acesso: 04 nov. 2019.

Gil, A. C. 2002. Como elaborar projetos de pesquisa. São Paulo: Atlas, 4. ed.

Gomes, M. F., Teixeira, A. C. E. de A. 2017. Da participação social nos licenciamentos ambientais: para além da audiência pública. Revista do Mestrado em Direito da Universidade Católica de Brasília, 11, 128-146. Disponível:

https://portalrevistas.ucb.br/index.php/rvmd/art icle/view/7781. Acesso: 06 abr. 2020.

IAIA - International Association for Impact Assessment. 2006. Public participation international best practice principles. Fargo,USA: IAIA. (Special Publication Series $\left.\mathrm{n}^{\mathrm{o}} 4\right)$.

Harvey, D. 2016. 17 Contradições e o fim do capitalismo. São Paulo: Boitempo.

IBRAM - Instituto Brasileiro de Mineração. 2019. Relatório Anual de Atividades: julho 2018 a junho 2019. Disponível: http://portaldamineracao.com.br/ibram/wpcontent/uploads/2019/07/relatorio-anaul-20182019.pdf. Acesso: 03 fev. 2020.

Lerner, F.; Jeronymo, C. A. L.; Pinto, A. E. M. 2016. Estudo de Impacto Ambiental e Audiência Pública: Instrumentos para participação popular na decisão ambiental? O caso de um gasoduto em Macaé, RJ, Brasil. Interespaço, 2, 328-354. doi: http://dx.doi.org/10.18766/24466549/interespaco.2,328-354

Lessa, S. 2013. Capital e Estado de Bem-Estar: o caráter de classe das políticas públicas. São Paulo: Instituto Lukács.

Lopes, V. M. C.; Oliveira, M. L. R. de. 2018. Novo marco legal para a mineração e suas implicações para a atividade minerária no Brasil sob a luz da justiça ambiental. PolÊm!ca, 18, 033-053.

doi: https://doi.org/10.12957/polemica.2018.39422

Loureiro, C. B. F. 2007. Emancipação. In: Ferraro Junior, L. A. (org.). 2017. Encontros e caminhos: formação de educadoras (es) 
ambientais e coletivos educadores. Vol. 2. Brasília: MMA, Diretoria de Educação Ambiental.

Maia, A. A. 2015. Importância da audiência pública como mecanismo de participação social em projetos de transportes. 2015. 165 p. Dissertação (Mestrado em Transportes) Universidade de Brasília. Brasília.

Mêncio, M.; Lotta, G.; Paulics, V. 2005. Realizar audiências públicas no município. Instituto Pólis: dicas para a ação municipal, São Paulo: Instituto Pólis, n. 229.

Melek, T. H. R.; Gonçalves, C. G. de O.; Aerosa, J.; Soares, V. M. N. 2017. Condições de trabalho numa mineradora: o olhar de trabalhadores e de profissionais da saúde e segurança. International Journal on Working Conditions, 13, 104-122. Disponível: http://ricot.com.pt/artigos/1/IJWC.13_TMelek \%20et\%20al._104.122.pdf. Acesso: 03 abr. 2020.

Milanez, B. 2014. Impactos da Mineração. Le Monde Diplomatique Brasil. Belém, 1-5. Disponível:

http://www.ufjf.br/poemas/files/2014/07/Milan ez-2010-Impactos-da-

minera\%C3\%A7\%C3\%A3o.pdf. Acesso: 07 out. 2019.

Moreira Neto, D. de F. 1997. Audiências públicas. Revista de Direito Administrativo, 210, 11-23. doi: http://dx.doi.org/10.12660/rda.v210.1997.4708 4

MPSP - Ministério Público de São Paulo. 2016. Núcleo de Políticas Públicas. Roteiro para a realização de audiências públicas e de escutas sociais. Disponível: http://www.mpsp.mp.br/portal/page/portal/cao _civel/Roteiro\%20Aud\%20P\%C3\%BAblica\% 20e\%20escuta\%20social.pdf. Acesso: 03 abr. 2020.

Patriarcha-Graciolli, S. R.; Carvalho, J. de. 2014. A participação popular na legislação ambiental brasileira: uma reflexão crítica de justiça ambiental. Multitemas, 45, 137-147. Disponível:

https://www.multitemas.ucdb.br/multitemas/art icle/view/242. Acesso: 03 abr. 2020.

Quintas, J. S. 2019. O pescarte e as concepções estruturantes da educação ambiental na gestão ambiental pública. In: Timóteo, G. M. (org). 2019. Educação ambiental com participação popular : avançando na gestão democrática do ambiente. Campos dos Goytacazes: EdUENF, 2. ed. rev. e ampl. 339 p.

Prestes, G. A. 2019. Políticas públicas de desenvolvimento para o fim do capitalismo.
Espaço e Economia: Revista Brasileira de Geografia Econômica, VII(14). doi: https://doi.org/10.4000/espacoeconomia.5606

Rawls, J. 2000. Uma Teoria da Justiça. Trad. Almiro Pisetta e Lenita M. R. Esteves. São Paulo: Martins Fontes.Rolim, L. B.; Cruz, R. de S. B. L. C.; Sampaio, K. J. A. de J. 2013. Participação popular e o controle social como diretriz do SUS: uma revisão narrativa. Saúde em Debate, 37(96), 139-147. doi: https://doi.org/10.1590/S010311042013000100016

Sánchez, L. E. 2013. Avaliação de impacto ambiental: conceitos e métodos. São Paulo: Oficina de Textos, 2. ed.

Santos, F. M. 2018. O modo de sociabilidade capitalista e o aprimoramento da sensibilidade humana. In: IV SERPINF- Seminário Regional de Políticas Públicas, Intersetorialidade e Família. II SENPINF- Seminário Nacional de Políticas Públicas, Intersetorialidade e Família: Marcas históricas e movimentos contemporâneos. Disponível: https://editora.pucrs.br/acessolivre/anais/serpin f-senpinf/assets/edicoes/2018/arquivos/60.pdf. Acesso: 17 jul. 2020.Santos, P. F. dos; Borges, L. A. C. 2019. Sustentabilidade do licenciamento ambiental minerário em Minas Gerais: caso aplicado. Engenharia Sanitária e Ambiental, 24, 463-472. doi: https://doi.org/10.1590/s141341522019175858

Silva, M. L.; Andrade, M. C. K. 2017. Os impactos ambientais da atividade mineradora. Caderno Meio Ambiente e Sustentabilidade, 11(6), 67$82 . \quad$ Disponível: https://www.uninter.com/cadernosuninter/inde x.php/meioAmbiente/article/view/541. Acesso: 18 mar. 2019.

Silva, D. N. S.; Gomes, E. T. A.; Serna, A. G. 2018. Dialética Contemporânea sobre Áreas de Preservação Permanente: Quando a Exceção a Cada vez mais é Legitimada como Regra. Revista Brasileira de Geografia Física, 11, 1162-1175. doi: https://doi.org/10.26848/rbgf.v11.3.p11621175Siqueira, L. de C. 2008. Política ambiental para quem? Ambiente \& Sociedade, 11, 425437. doi: https://doi.org/10.1590/S1414753X2008000200014

Vasconcelos, A. M. 1985. A Intenção-Ação no Trabalho Social: Uma contribuição ao debate sobre a relação assistente social-grupo. São Paulo: Editora Cortez.

Vasconcelos, P. T. 2002. A audiência pública como instrumento de participação popular na avaliação do Estudo de Impacto Ambiental. 
2002. 199 p. Dissertação (Mestrado em Direito) - Universidade Federal de Pernambuco. Recife. Wampler, B.; Avritzer, L. 2011. Que tipo de resultados devemos esperar das instituições participativas. In: Pires, R. R. C. (Orgs.). A efetividade das instituições participativas no Brasil: estratégias de avaliação. Brasília (DF): Instituto de Pesquisa Econômica Aplicada.
Wanderley, L. J.; Mansur, M. S.; Milanez, B.; Pinto, R. G. 2016. Desastre da Samarco/Vale/BHP no Vale do Rio Doce: aspectos econômicos, políticos e socio ambientais. Ciência e Cultura, 68, 30-35. doi: http://dx.doi.org/10.21800/231766602016000300011 